\title{
O papel do Programa Bolsa Família na segurança alimentar das famílias do Território do Marajó, PA
}

\author{
The role of Programa Bolsa Família in the food security of families in the Marajó \\ Territory, PA, Brazil
Le rôle de Programa Bolsa Família sur la sécurité alimentaire des familles du Territoire de Marajó, PA, Brésil
El papel del Programa Bolsa Família en la seguridad alimentaria de las familias en el Territorio de Marajó, PA, Brasil

\author{
Elcio Costa Nascimento ${ }^{1}$ \\ João Paulo Leão de Carvalho ${ }^{1}$ \\ Benedito Ely Valente da $\mathrm{Cruz}^{2}$ \\ Miqueias Freitas Calvi ${ }^{3}$
}

Recebido em 11/10/2016; revisado e aprovado em 19/04/2017; aceito em 19/04/2017

DOI: http://dx.doi.org/10.20435/inter.v18i2.1414

\begin{abstract}
Resumo: Este trabalho objetiva analisar o papel que o Programa Bolsa Família desenvolve na segurança alimentar das famílias do Território do Marajó, PA. Utilizando abordagem qualitativa, buscou-se compreender a influência do benefício nas práticas alimentares, econômicas e sociais. Observou-se impacto positivo na alimentação e no padrão de vida local, proporcionando bem-estar, melhora na qualidade de vida e desenvolvimento de práticas creditícias, importantes no combate à insegurança alimentar na região.
\end{abstract}

Palavras-chave: programas sociais; práticas creditícias; hábitos alimentares.

\begin{abstract}
This paper aims to analyze the role that Programa Bolsa Familia plays in the food security of the families in the Marajó Territory, located in the State of Pará, Brazil. Using a qualitative approach, we sought an understanding of the benefit of the program's influence in food, economic and social practices. A positive impact was observed in access to food and standard of living, providing well-being, better quality of life and development of credit practices, necessary to combat food insecurity in the region.
\end{abstract}

Key words: social programs; eating habits; credit practices.

Résumé: Ce travail vise à analyser le rôle du Programa Bolsa Família sur la sécurité alimentaire des ménages dans le Territoire de Marajó, État du Pará, Brésil. Avec l'aide d’une approche qualitative, nous cherchons à comprendre l'influence positive dans les habitudes alimentaires et pour les acteurs économiques et sociaux. Nous avons observé un impact certain sur l'offre et le modèle de vie local, assurant le bien-être, l'amélioration de la qualité de vie et le développement de l'usage de prêts, importante pour la lutte contre l'insécurité alimentaire dans la région.

Mots-clés: les programmes sociaux; habitudes alimentaires; pratiques de crédits.

Resumen: Este trabajo tiene como objetivo analizar el papel que el Programa Bolsa Família desarrolla en la seguridad alimentaria de las familias del Territorio del Marajó, en el Estado de Pará, Brasil. Utilizando un abordaje cualitativo, se buscó incluir la influencia del beneficio del Programa en las prácticas alimentarias, económicas y sociales. Se observó un impacto positivo en la alimentación y en el estándar de vida local, proporcionando el bienestar, mejoras a la calidad de vida y el desarrollo de prácticas acreedoras, importantes para combatir la inseguridad alimentaria en la región.

Palabras clave: programas sociales; hábitos alimenticios; prácticas acreedoras.

\footnotetext{
${ }^{1}$ Universidade Federal do Pará (UFPA), Belém, Pará, Brasil.

${ }^{2}$ Universidade Estadual do Pará (UEPA), Belém, Pará, Brasil.

${ }^{3}$ Universidade Federal do Pará (UFPA), Altamira, Pará, Brasil.
} 


\section{INTRODUÇÃO}

Programas de transferência direta de renda condicionada têm como objetivos o alívio imediato da pobreza e da extrema pobreza em curto prazo, a elevação do investimento no capital humano em longo prazo e, principalmente, a quebra do ciclo de transmissão da pobreza entre as gerações (HODDINOTT; SKOUFIAS, 2003; ATTANASIO; MESNARD, 2005; BORRAZ; GONZALEZ, 2009; PAES-SOUSA; SANTOS; MIAZAKI, 2011; OSORIO; SOUZA, 2012).

Desde a década de 1990, esses programas têm se tornado a principal ferramenta de proteção social na maioria dos países latino-americanos e do Caribe e têm se constituído como ferramentas efetivas na promoção do acesso à educação, serviços de saúde e na garantia da segurança alimentar para as famílias mais pobres, devido às condicionalidades envolvidas na área da educação e da saúde (HODDINOTT; SKOUFIAS, 2003; BEHRMAN; PARKER; TODD, 2005; LINDERT, 2005; HARVEY; SAVAGE, 2006; ASSUNÇÃO; LEITÃO; INÁCIO, 2012).

As condicionalidades, metas e deveres que as famílias beneficiárias necessitam cumprir em vista a permanecerem no programa, não devem ser vistas como obrigações impostas, mas como uma espécie, segundo Lindert (2005), de "contrato social" entre o governo, responsável pelo repasse do recurso, e os beneficiários, que se comprometem a matricular na escola crianças e adolescentes dos 6 aos 17 anos e obter frequência mínima de 75\%, além de garantir a vacinação e o acompanhamento de peso e crescimento de crianças até 7 anos e pré-natal das gestantes nas unidades de saúde (BRASIL, 2016a), colaborando, de forma mútua, para o alcance dos objetivos principais do programa tanto em curto quanto em longo prazo.

No Brasil, o Programa Bolsa Família (PBF) surge da unificação de quatro outros programas pré-existentes de transferência de renda: Bolsa Escola (Ministério da Educação), Bolsa Alimentação (Ministério da Saúde), Auxílio Gás (Ministério das Cidades) e Cartão Alimentação (Ministério de Segurança Alimentar ${ }^{4}$ ) como estratégia de combate à desigualdade social, à extrema pobreza e à fome (LINDERT, 2005; SANTOS; PASQUIM; SANTOS, 2011).

Nesse contexto, segundo Silva et al. (2007) a desnutrição no Brasil está fortemente ligada à baixa renda, o que prejudica o acesso a uma alimentação em quantidade e em qualidade, de acordo com o conceito de segurança alimentar proposto pela Lei Orgânica de Segurança Alimentar e Nutricional (LOSAN) - Lei n ${ }^{\circ} 11.346 / 06$, que instituiu a Política Nacional de Segurança Alimentar (BRASIL, 2006).

Nessa perspectiva, foi criado o Programa Fome Zero em 2003, tendo como foco principal a segurança alimentar e o acesso a uma alimentação adequada como direito humano (ASSUNÇÃO; LEITÃO; INÁCIO, 2012), seguindo acordos internacionais, entre os quais a Declaração do Milênio, da Organização das Nações Unidas (ONU), que, entre seus objetivos, inclui a erradicação da pobreza e a promoção do desenvolvimento humano, propondo a redução para a metade, até ao ano 2015, da "percentagem de habitantes do planeta com rendimentos inferiores a um dólar por dia e a das pessoas que passam fome [...]" (ONU, 2000).

Portanto um dos eixos de ação do Programa Fome Zero é garantir uma renda mínima a essa população, através de programas de transferência de renda. Segundo Cotta e Machado (2013), "os programas de transferência condicionada de renda têm-se destacado como políticas de proteção

\footnotetext{
${ }^{4}$ O MESA (Ministério Extraordinário de Segurança Alimentar e Combate à Fome) foi criado no início do Governo do Presidente Luís Inácio Lula da Silva em 2003 e transformado em MDS (Ministério do Desenvolvimento Social e Combate à Pobreza) em 2004.
} 
social e combate à pobreza em diversos países, inclusive no Brasil". Nesse eixo, encontra-se o PBF, que objetiva o alívio imediato da pobreza por meio de repasse direto de recurso monetário, o acesso a direitos básicos na área da educação, saúde e assistência social e o desenvolvimento das famílias com o apoio de ações e programas complementares (BRASIL, 2016a).

Em janeiro de 2016, o PBF beneficiou quase 14 milhões de famílias com repasses médios de $\mathrm{R} \$ 163,57$ (BRASIL, 2016c) por núcleo familiar. O valor total transferido pelo governo federal às famílias atendidas ultrapassou os R\$ 2 bilhões, representando cerca de $0,4 \%$ do Produto Interno Bruto (PIB) do país.

Segundo Neri, Vaz e Souza (2013), além dos impactos sociais, o PBF representa impacto significativo na atividade econômica, visto que cada $R \$ 1,00$ investido no programa representa um aumento de $\mathrm{R} \$ 1,78$ no PIB. Quando comparado a outros programas, o PBF tem, numa relação de custo $x$ benefício, um efeito amplamente positivo para a economia do país ${ }^{5}$.

No Estado do Pará, segundo o Relatório de Informações Sociais do Brasil (RIS) (BRASIL, 2016d), no mesmo período havia 1.376.705 famílias registradas no Cadastro Único para Programas Sociais do Governo Federal (CADÚnico), que detinham renda de até meio salário mínimo per capta ou renda total de até três salários mínimos (BRASIL, 2016b). Desse total, 913.985 famílias recebiam o benefício do Bolsa Família. No Território do Marajó, eram 99.619 famílias cadastradas (7\%) e 78.573 famílias beneficiárias, ou 8,6\% do total do Estado do Pará (BRASIL, 2016c). Essa participação no Programa movimentou $R \$ 17.617 .230,00$, representando uma injeção de recursos significativa na economia do Território e dos municípios que o integram.

A partir desse conjunto de informações, este trabalho objetiva avaliar as relações do Programa Bolsa Família com a segurança alimentar, a alimentação, o consumo e o modo de vida das famílias no Território do Marajó.

\section{METODOLOGIA}

O Território do Marajó é formado por dezesseis (16) municípios, que compõem a Mesorregião Geográfica do Marajó. Essa mesorregião tem uma área territorial de 104.140 km² (IBGE, 1992), distribuída em três microrregiões geográficas (MRG): Arari, Furo de Breves e Portel. As duas primeiras compreendem municípios inseridos integralmente no Arquipélago do Marajó. Já a MRG de Portel abrange municípios com sedes em áreas continentais, na porção sul/sudoeste da mesorregião (Figura 1).

\footnotetext{
${ }^{5}$ O Benefício de Prestação Continuada (BPC) consome 0,6\% do PIB, com geração de R\$ 1,54 e consumo e R\$ 1,19 no PIB. O seguro-desemprego, cujos gastos alcançam também 0,6\% do PIB, rende $\mathrm{R} \$ 1,34$ em consumo e $\mathrm{R} \$ 1,09$ no PIB (NERI; VAZ; SOUZA, 2013).
} 


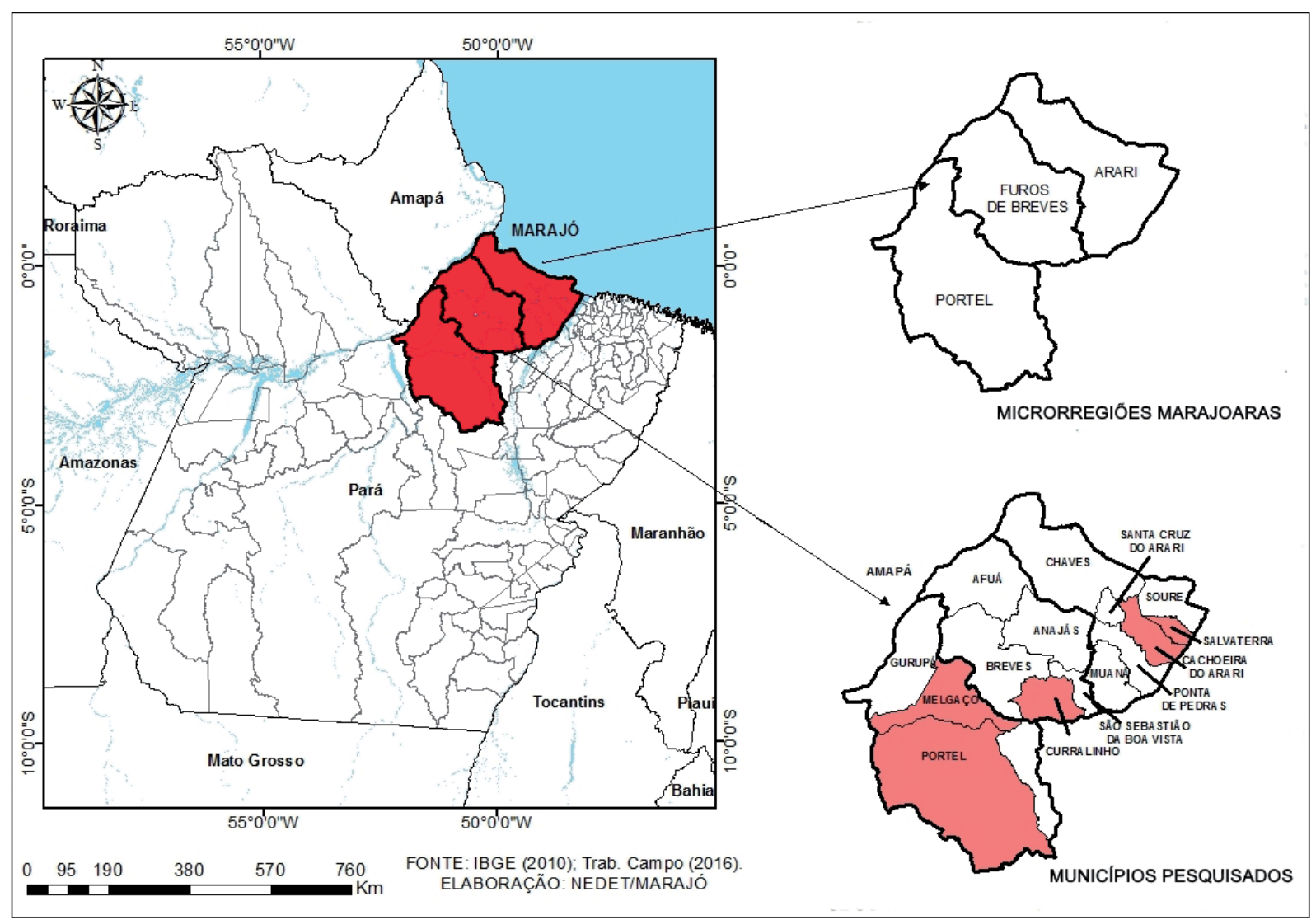

Figura 1 - Mapa do Território do Marajó, suas microrregiões e municípios pesquisados

A pesquisa de campo foi realizada em cinco municípios do território do Marajó (Cachoeira do Arari, Salvaterra, Curralinho, Melgaço e Portel) no período de agosto a novembro de 2015. $\mathrm{Na}$ oportunidade, foram realizadas 50 entrevistas com famílias beneficiárias do Programa Bolsa Família. Objetivou-se, com esses cinco municípios, alcançar famílias pertencentes às três microrregiões do Marajó, buscando obter, dessa forma, maior amplitude e representatividade territorial das informações, tendo em vista a diversidade de realidades existentes na região. Os dados foram coletados por meio de entrevista semiestruturada e registro de áudio, seguindo as recomendações de Poulain e Proença (2003) e listagem livre, conforme orientam Santos e Coelho-Ferreira (2012).

As entrevistas semiestruturadas tiveram por objetivo estimular o entrevistado a falar abertamente, porém sem perder o foco e o direcionamento da pesquisa. Buscou-se criar um ambiente confortável, no qual as famílias entrevistadas pudessem se expressar livremente, sem as limitações de um questionário. As conversas foram gravadas, anotadas e posteriormente transcritas para favorecer a análise. O roteiro foi dividido em três seções: a) dados socioeconômicos e hábitos alimentares; b) informações sobre (in)segurança alimentar; e c) informações sobre o destino dado aos recursos recebidos pelo Programa, com dois focos: um geral, tratando dos gastos realizados com o benefício, e outro específico, voltado aos gastos com alimentação.

A listagem livre parte do princípio de que os produtos primeiramente citados e com maior frequência são os que têm maior importância cultural (SANTOS; COELHO-FERREIRA, 2012). Essa técnica foi utilizada para identificar os alimentos mais consumidos e, portanto, mais importantes na alimentação diária das famílias do Território do Marajó e as mudanças nas práticas alimentares ao longo do tempo, na medida do possível a ser observado. 


\section{RESULTADOS E DISCUSSÃO}

O rendimento, proveniente dos benefícios do governo federal, aparece como a principal fonte de renda fixa das famílias. Além do benefício do Programa Bolsa Família, a aposentadoria e o seguro defeso foram citados pelas famílias entrevistadas. Das 50 famílias, 18 (36\%) declararam ter alguém do grupo familiar que recebe a aposentadoria e 13 (26\%) que contavam com o seguro-defeso, um benefício financeiro temporário fornecido aos pescadores durante o período do defeso. A maioria dos entrevistados foi de mulheres (73\%) com renda inferior a 1 (um) salário mínimo (36\%), idade entre 40 e 50 anos (25\% e 21\%, respectivamente) e com baixo nível de escolaridade (75\% com ensino fundamental incompleto), tendo estudado até o 5 o ano (29\%). O número predominante de pessoas por unidade familiar ficou na faixa de 2 (duas) a 4 (quatro) pessoas (52\%).

Segundo o Relatório de Informações Sociais (BRASIL, 2016c), em janeiro de 2016, os cinco municípios pesquisados tinham 30.563 famílias cadastradas no CADÚnico e de 23.282 beneficiários (Tabela 1), representando um montante de mais de $\mathrm{R} \$ 5$ milhões provenientes do PBF mensalmente. Esse montante tem um impacto significativo na economia desses municípios, tendo em vista que as famílias beneficiárias, quando recebem o recurso, fazem parte de suas despesas mensais nas sedes municipais.

Tabela 1 - Famílias cadastradas, beneficiárias e valor do repasse do PBF nos municípios pesquisados, em janeiro de 2016

\begin{tabular}{lccc}
\hline \multicolumn{1}{c}{ Municípios } & $\begin{array}{c}\text { Total de famílias } \\
\text { cadastradas }\end{array}$ & $\begin{array}{c}\text { Famílias beneficiadas } \\
\text { PBF }\end{array}$ & $\begin{array}{c}\text { Valor total recebido } \\
\text { (R\$) }\end{array}$ \\
\hline Cachoeira do Arari & 5.256 & 3.613 & $928.966,00$ \\
Curralinho & 5.779 & 4.305 & $949.532,00$ \\
Melgaço & 4.335 & 3.489 & $945.806,00$ \\
Portel & 9.470 & 7.683 & $1.752 .778,00$ \\
Salvaterra & 5.723 & 3.496 & $733.564,00$ \\
\hline \multicolumn{1}{c}{ TOTAL } & $\mathbf{3 0 . 5 6 3}$ & $\mathbf{2 2 . 5 8 6}$ & $\mathbf{5 . 3 1 0 . 6 4 6 , 0 0}$ \\
\hline
\end{tabular}

Fonte: Brasil (2016c).

\subsection{MAIS COMIDA, MAIS ALIMENTO, MAIS COISAS PARA A CASA}

Como programa de transferência direta de renda, o pagamento mensal recebido do PBF, segundo as famílias, possui significativa relevância dentro das estratégias de reprodução desenvolvidas pela unidade familiar. Esse recurso é investido na compra de material escolar e uniforme para as crianças, na aquisição de equipamentos eletrônicos e outros bens (como geladeira, televisão, ventilador e bicicleta) e, principalmente, na aquisição de alimentos, demonstrando que o Bolsa Família tem importante influência nas práticas alimentares e na garantia da segurança alimentar das famílias marajoaras, como fica evidenciado nas falas dos entrevistados.

Pra roupa, pra remédio, pro alimento, pra tudo eu tiro desse dinheiro, pra me manter, eu e meus filhos. (Ribeirinha, Portel).

Quando chega o tempo do meu benefício, eu venho, 'arrecebo' [recebo] compro meu pirão, né? Arroz, feijão, carne, frango. (Pescador, Melgaço). 
Os primeiros referenciais em relação às práticas alimentares são apreendidos no convívio familiar, no qual o indivíduo tem o primeiro contato com o alimento, pois a família é considerada o centro "da organização do consumo alimentar" (CANESQUI, 1988, p. 212). Na realidade Amazônica, a prática alimentar largamente difundida concentra-se no binômio peixe e mandioca (MURRIETA, 2001; ADAMS; MURRIETA; SANCFHES, 2005). Prática amplamente observada entre os entrevistados, que informaram o consumo constante de peixe associado à farinha de mandioca nas refeições (almoço e jantar). Porém, no caso do Marajó, um outro elemento é essencial na alimentação: o açaí. Essa fruta é a base da alimentação das famílias locais e está presente em todas as principais refeições (almoço e jantar) e sua carência ou falta chega a ser caracterizada como ausência de alimentação, como observado na fala abaixo:

Pode o prato tá cheio de comida, se não tiver o açaí a gente come e não enche a barriga. E a comida pode ser um pedacinho, mas se tiver uma tigelinha de açaí, a gente come e a gente enche. (Agricultora, Portel).

Essa característica se deve à facilidade de acesso e à alta disponibilidade desse fruto na região, resultando em uma prática alimentar influenciada pelo meio e pelos recursos disponíveis. A realidade local demonstra o desenvolvimento de práticas alimentares com elevado grau de adaptação ao ambiente, construídas pelas famílias locais ao longo do tempo. A influência do meio ambiente e dos recursos naturais no desenvolvimento de práticas alimentares e na formação de uma identidade alimentar, cultural e social pode ser observada nos trabalhos de Murrieta et al. (1989), Morán (1990), Brondízio e Neves (1997), Acevedo Marin e Castro (1998), Maciel (2001) e Setton (2002).

Tais práticas, porém, podem se alterar ao longo do tempo. Bourdieu (2009) afirma que as condições sociais e econômicas podem modificar determinados hábitos. O acesso ou a restrição a um determinado alimento, a mudança para outros lugares, questões ambientais e/ou econômicas podem influenciar nas práticas alimentares. Nesse contexto, a renda do benefício influencia diretamente nas práticas alimentares das famílias marajoaras, uma vez que o aporte econômico recebido colabora para a obtenção de uma alimentação mais variada e com maior número de produtos, permitindo o acesso a alimentos que eram pouco ou não acessíveis devido à escassez de renda, mas sem acarretar na perda das características culturais e sociais presentes nas práticas alimentares desenvolvidas, conservando "a memória e o peso do aprendizado alimentar e algumas das formas sociais aprendidas" na convivência familiar e influenciadas pelo meio e pela sociedade do entorno (MINTZ, 2001, p. 32).

As famílias, na época do pagamento do benefício, aproveitam a ida às sedes dos municípios para adquirir os alimentos que não são oferecidos em suas unidades de produção nas feiras, mercados locais e/ou em supermercados. Entre os principais produtos obtidos pelas famílias, estão a carne vermelha, o arroz, o feijão, o açúcar, o café e refrigerantes. A compra de produtos industrializados, como sardinha em conserva, salsicha, carne enlatada e macarrão instantâneo, também foi comum nas falas dos entrevistados, demonstrando um aumento na inclusão desses alimentos nas práticas alimentares das famílias locais. Trata-se de alimentos que são ricos em sódio e que por isso, segundo Philippi et al. (1999), devem ser de consumo moderado. Bem Lignani et al (2010) observou a mesma situação em pesquisa sobre mudanças no consumo alimentar de famílias brasileiras beneficiárias do Bolsa Família. Esse fenômeno foi observado devido ao baixo custo desses alimentos, à praticidade e à grande aceitação por parte das crianças e dos jovens, demonstrando-se a necessidade de atividades que tratem da importância da construção de há- 
bitos alimentares saudáveis entre os beneficiários do Programa, como observado em programas semelhantes como Progressa (México), no qual as famílias são "encorajadas a ter uma dieta mais variada, incluindo mais frutas, vegetais, leite e outros produtos de origem animal" (HODDINOTT; SKOUFIAS, 2003, p. 27).

Durante a pesquisa, foram observadas falas referentes a um passado de dificuldades, notadamente econômicas, impedindo as famílias de terem um acesso regular e permanente aos alimentos, com momentos de escassez e falta de algo para sua alimentação. Embora o recurso recebido não seja suficiente para garantir o alimento durante todo o mês, seu recebimento permite às famílias desenvolverem estratégias que permitem a sobrevivência e a permanência de seu modo de vida.

Antes, assim, eu não sabia o que era comer um feijão, comer um arroz, um macarrão, uma comida temperada com uma cebola, um óleo. (Produtora, Portel).

Aumentou [consumo de diversos tipos de alimentos] porque antes não tinha condição de comprar, não tinha dinheiro. (Pescadora, Salvaterra).

O início da participação no programa permitiu que a renda proveniente das atividades locais, entre elas a da produção da farinha, do açaí, do extrativismo da madeira, da comercialização das frutas, dos peixes e do camarão, fosse redirecionada para outros fins, como o pagamento de dívidas, a compra de ferramentas de trabalho e insumos e de roupas. O benefício, dessa forma, colabora tanto na garantia da alimentação diária, quanto na formação das estratégias em favor da unidade familiar.

Em estudo sobre as percepções da sociedade brasileira sobre o PBF, Castro et al. (2009) observaram questões semelhantes em que a renda do programa proporciona condições favoráveis para a compra de "mais alimentos", "mais coisas para a casa" e "mais material escolar". A alimentação, segundo o IBASE (2008), também aparece como o principal destino dado ao benefício recebido pelas famílias, em $87 \%$ das situações, seguido pelo gasto com material escolar $(46 \%)$ e vestuário $(37 \%)^{6}$. Essa característica revela que a renda proveniente do PBF possibilita o acesso a um padrão de consumo maior e a compra de bens não acessíveis anteriormente pelas famílias. Estes gastos seguem questões estratégicas determinadas pelos próprios beneficiários, visando, sempre, ao "melhor interesse" dos familiares (SAVE THE CHILDREN, 2005).

Outro papel importante proporcionado pelo benefício é colaborar na permanência e reprodução do modo de vida local em épocas de significativa dificuldade de produção e geração de renda, como no inverno amazônico (janeiro a maio/junho). Nesse período, com a entressafra do açaí, a redução na produção de peixes e o aumento das chuvas, segundo os entrevistados, aumentam as dificuldades de garantia de uma alimentação de qualidade e constante das famílias. As atividades agrícolas normalmente desenvolvidas, como a broca, a derruba e a capina, diminuem ou ficam impraticáveis. Os recursos recebidos acabam se tornando a principal fonte de renda para muitas famílias, enquanto que as demais atividades (roça, pesca e extrativismo) voltam-se para o autoconsumo, tornando, assim a renda "certa" dos benefícios sociais a única renda confiável e que garante o acesso a uma alimentação variada e em quantidade, colaborando com efeito positivo na redução da fome no território marajoara.

\footnotetext{
${ }^{6}$ Outros estudos relatam semelhante situação (SAVE THE CHILDREN, 2005; HARVEY; SAVAGE, 2006; BURLANDY, 2007; DUARTE; SAMPAIO; SAMPAIO, 2009; PAES-SOUSA; SANTOS; MIAZAKI, 2011; ASSUNÇÃO; LEITÃO; INÁCIO, 2012).
} 
A segurança alimentar de uma população, segundo Hoffman e Kageyama (2007), não é combatida apenas com "a elevação do poder aquisitivo", mas com o aumento dos "direitos dos pobres", proporcionando, dessa forma, o acesso à alimentação de qualidade e em quantidade suficiente para suprir necessidades, somada ao acesso a condições básicas necessárias para reprodução social e cultural das comunidades. Essa afirmação coaduna com a Lei Orgânica de Segurança Alimentar e Nutricional (Lei № 11.346/06), que define a SAN como "a realização do direito de todos ao acesso regular e permanente a alimentos de qualidade, em quantidade suficiente, sem comprometer o acesso a outras necessidades essenciais" de acesso à educação, saneamento, saúde, cidadania, entre outras.

\subsection{Confiabilidade e práticas creditícias}

Eu não tinha crédito para tá comprando. Agora não! Graças a Deus, venho aqui, eu levo toda nossa comida. Só não dá pra demorar. (Ribeirinha, Melgaço).

Eles [regatão, barqueiro, comerciante] me vendem fiado, quando eu recebo o Bolsa, eu pago. (Ribeirinha, Portel).

A prática do "fiado", ato de "vender uma mercadoria ou prestar um serviço mediante a promessa verbal de pagamento futuro" (CASTELLS; GUIMARÃES, 2007), é um costume amplamente difundido entre as práticas creditícias informais no território brasileiro, e sua prática vem sendo desenvolvida ao longo de muitos anos, desde o período colonial (SANTOS, 2012).

Essa prática é baseada "na confiança e na boa fé" entre o comerciante e o freguês, envolvendo, portanto, muito mais do que uma simples relação econômica, mas relações de amizade, "de fé", de "boa fé", baseada em "conhecimentos pessoais" e "essencialmente no poder da palavra" (GUIMARÃES, 2007; SANTOS 2012). Portanto o não pagamento da dívida, do fiado, representa a quebra dessa confiança entre os envolvidos e o rompimento da justiça existente nessa prática. Por isso, segundo Castells e Guimarães (2007), existe uma tensão nessa relação que mistura um pouco de "amistosidade e hostilidade", sendo a pessoa que não faz jus ao seu dividendo, pode ser considerada não apenas um devedor, mas um "criminoso".

Nesse contexto, o recebimento do benefício, em seu caráter fixo e constante, possibilita a realização desse tipo de prática creditícia, do fiado, pelas famílias beneficiárias, tendo impacto positivo tanto na vida quanto na alimentação das famílias marajoaras. Antes da participação no Bolsa Família, segundo os entrevistados, era difícil a compra do alimento "fiado", principalmente nas mercearias das comunidades, uma vez que as famílias não possuíam recursos suficientes para arcar com o pagamento. Eram carentes, portanto, do grau de confiança necessário para o desenvolvimento desse tipo de relação junto aos comerciantes locais. Após a participação no programa, caso falte ou acabe o alimento na unidade familiar, é possível "pegar na venda" a comida necessária para suprir um ou vários dias, e pagar essa dívida após o recebimento do benefício, honrando assim o contrato social gerado e podendo, caso necessário, restabelecê-lo. Através dessas práticas, as famílias compram de tudo: farinha, arroz, feijão, macarrão, alimentos industrializados (salsichas, sardinhas, enlatados, macarrão instantâneo), biscoitos, refrigerantes, entre outros produtos. Essa realidade causa impacto positivo na redução da insegurança alimentar das famílias locais, as quais, anteriormente, sem crédito no mercado, chegavam a ficar sem alimento, ou seja, passando fome, situação que não se repete atualmente, devido ao caráter 
de confiabilidade mútua oferecido pelo recebimento dessa renda extra. A mesma situação foi reportada por Save the Children (2005) no Sudeste da África.

Outra característica dos programas de transferência de renda nas comunidades é o impacto positivo da injeção de dinheiro extra nos mercados locais. As famílias beneficiárias aproveitam a época do recebimento e/ou pagamento do benefício para comprar tanto os alimentos, quantos os demais produtos necessários para a reprodução social delas nas sedes dos municípios, causando dessa forma impacto direto no comércio local tanto nas cidades quanto nas comunidades. Neri, Vaz e Souza (2013) comentam do "papel positivo" que os programas sociais de transferência de renda desenvolvem, contribuindo com a redução da pobreza e da desigualdade social, além do efeito amplamente positivo na economia do país, diretamente relacionado com impactos no PIB nacional. Harvey e Savage (2006) observaram, em países africanos, o impacto positivo que os programas de transferência de renda ocasionam nos mercados locais "através do aumento do poder aquisitivo dos beneficiários e do aumento da compra de produtores locais".

\section{CONSIDERAÇÕES}

A renda proveniente dos programas de transferência condicionada de renda, neste caso do Programa Bolsa Família, tem impacto significativo no combate à fome e à insegurança alimentar e nutricional das famílias marajoaras. Contribui tanto diretamente, quanto indiretamente, através das práticas creditícias, ao acesso a uma alimentação variada, assim como de produtos não alimentares, adquiridos nos mercados locais, lojas, feiras e supermercados nas sedes dos municípios, necessários para suprir as necessidades das famílias, sem contudo acarretar perda de características culturais e sociais presentes nas práticas alimentares desenvolvidas ao longo dos anos, como o consumo do açaí, fruta cujo consumo é parte importante na alimentação marajoara. O programa promove e fortalece as relações de confiabilidade entre os beneficiários e comerciantes locais, possibilitando o desenvolvimento de práticas creditícias como "o fiado", necessárias para garantir o acesso regular ao alimento, contribuindo com a redução da fome entre as famílias marajoaras. Porém observou-se o consumo de alimentos com baixa qualidade nutricional (produtos industrializados, doces e refrigerantes), ricos em sódio e açúcares, demonstrando a necessidade de promoção de atividades paralelas junto às famílias beneficiárias, principalmente no que concerne ao desenvolvimento de práticas alimentares mais saudáveis.

\section{REFERÊNCIAS}

ACEVEDO MARIN, Rosa; CASTRO, Edna. Negros do Trombetas: guardiães de matas e rios. 2. ed. Belém: Cejup/UFPA/NAEA, 1998.

ADAMS, Cristina; MURRIETA, Rui Sergio S.; SANCHES, Rosely A. Agricultura e alimentação em populações ribeirinhas das Várzeas do Amazonas: novas perspectivas. Ambiente \& Sociedade, v. 8, n. 1, jan./jun. 2005.

ASSUNÇÃO, Viviane Kraieski; LEITÃO, Maria do Rosário de F. A.; INÁCIO, Pedro Henrique Dias. Comer mais e melhor: os impactos do Programa Bolsa Família na alimentação de famílias de pescadoras artesanais de Pernambuco. Amazônica, Belém, v. 4, n. 2, 2012.

ATTANASIO, Orazio; MESNARD, Alice. The impact of a conditional cash transfer Programme on consumption in colombia. Centre for the evaluation of development policies: the institute for fiscal studies, 2005.

BEHRMAN, Jere Richard; PARKER, Susan; TODD, Petra Elisabeth. Long-term impacts of the oportunidades conditional cash transfer program on rural youth in Mexico. Ibero America Institute for Economic Research, Discussion papers n. 122, 2005. 
BEM LIGNANI, Juliana de et al. Changes in food consumption among the Programa Bolsa Família participant families in Brazil. Public Health Nutrition, v. 14, n. 5, 2010.

BORRAZ, Fernando; GONZALEZ, Nicolás. Impact of the Uruguayan Conditional Cash Transfer Program. Cuadernos de Economía, Colombia, v. 46, 2009.

BOURDIEU, Pierre. A economia das trocas simbólicas. São Paulo: Perspectiva, 2009.

BRASIL. Ministério do Desenvolvimento Social e Combate à Pobreza. Bolsa Família. Brasília, 2016a. Disponível em: <http://mds.gov.br/assuntos/bolsa-familia/o-que-e>. Acesso em: 9 fev. 2016.

Cadastro Único. Brasília, 2016b. Disponível em: <http://www.mds.gov.br/bolsafamilia/ cadastrounico>. Acesso em: 15 fev. 2016.

Relatórios de Informações Sociais: RI Bolsa Família e Cadastro Único. Brasília, 2016c. Disponível em: <http://aplicacoes.mds.gov.br/sagi/RIv3/geral/index.php>. Acesso em: 15 fev. 2016.

Relatórios de Informações Sociais. Brasília, 2016d. Disponível em: <http://aplicacoes.

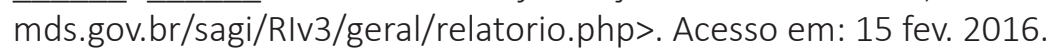

Lei n. 11.346, de 15 de setembro de 2006. Cria o Sistema Nacional de Segurança Alimentar e Nutricional - SISAN com vistas em assegurar o direito humano à alimentação adequada e dá outras providências. Brasília, 2006.

BRONDíZIO, Eduardo; NEVES, Walter. A. Populações caboclas do estuário do Amazonas: a percepção do ambiente natural. In: PAVAN, C. (Org.). Uma estratégia latino americana para Amazônia. São Paulo: Editora UNESP, 1997. v. 1.

BURLANDY, Luciene. Transferência condicionada de renda e segurança alimentar e nutricional. Ciência \& Saúde Coletiva, v. 12, n. 6, p. 1441-1451, 2007

CANESQUI, Ana Maria. Antropologia e alimentação. Revista Saúde Pública, São Paulo, v. 22, n. 3, 1988.

CASTRO, Henrique Carlos de Oliveira; WALTER, Maria Inez Machado Telles; SANTANA, Cora Maria Bender de; STEPHANOU, Michelle Conceição. Percepções sobre o Programa Bolsa Família na sociedade brasileira. Opinião Pública, Campinas, SP, v. 15, n. 2, p. 333-355, n. 2009.

COTTA, Rosângela Minardi Mitre; MACHADO, Juliana Costa. Programa Bolsa Família e segurança alimentar e nutricional no Brasil: revisão crítica da literatura. Revista Panamericana de Salud Pública, v. 33, n. 1, p. 54-60, 2013.

CASTELLS, Alicia Norma González de; GUIMARÃES, Ana Cristina Rodrigues. Pinceladas sobre as práticas comerciais em um bairro popular de Florianópolis. Cuadernos de Antropología Social, n. 26, 2007.

DUARTE, Gisléia Benini; SAMPAIO, Breno; SAMPAIO, Yony. Programa Bolsa Família: impacto das transferências sobre os gastos com alimentos em famílias rurais. RESR, Piracicaba, SP, v. 47, n. 4, p. 903918, out./dez. 2009.

GUIMARÃES, Ana Cristina Rodrigues. Comerciantes de bairro: seus discursos, suas práticas. In: REUNIÓN DE ANTROPOLOGÍA DEL MERCOSUR (RAM)- Desafíos Antropológicos, 7., Porto Alegre, RS, 23-26 jul. 2007. Anais... Porto Alegre: UFRGS, 2007.

HARVEY, Paul; SAVAGE, Kevin. Oxfam GB Malawi and Zambia Emergency Cash Transfer Projects: a Synthesis of key learning. Overseas Development Institute. Humanitarian Policy Group, 2006.

HODDINOTT, John; SKOUFIAS, Emmanuel. The impact of progressa on food consumption. Food Consumption and Nutrition Division. Discussion paper, n. 150. Washington: FCND, 2003.

HOFFMANN, Rodolfo; KAGEYAMA, Angela. Pobreza, insegurança alimentar e pluriatividade no Brasil. Londrina: SOBER, 2007. Disponível em: <http://www.sober.org.br/palestra/6/1159.pdf>. Acesso em: 10 nov. 2012.

INSTITUTO BRASILEIRO DE ANÁLISES SOCIAIS E ECONÔMICAS (IBASE). Repercussões do Programa Bolsa Família na segurança alimentar e nutricional das famílias beneficiadas. Documento síntese. Rio de Janeiro: IBASE, jun. 2008. 
INSTITUTO BRASILEIRO DE GEOGRAFIA E ESTATÍSITCA (IBGE). Censo Demográfico 1991: Resultados preliminares. Rio de Janeiro: IBGE, 1992.

LINDERT, Kathy. Brazil: Bolsa Familia Program - scaling-up cash transfers for the poor. MfDR Principles in Action: Sourcebook on Emerging Good Practices. Executive Sumary. 2005. Disponível em: <http://www. mfdr.org/sourcebook/6-1Brazil-BolsaFamilia.pdf>. Acesso em: 20 out. 2015.

MACIEL, Maria Eunice. Cultura e alimentação ou o que têm a ver os Macaquinhos de Koshima com BrillatSavarin? Horizontes antropológicos, Porto Alegre, ano 7, n. 16, 2001.

MINTZ, Sidney W. Food and anthropology: a brief overview. Revista Brasileira de Ciências Sociais, São Paulo, v. 16, n. 47, out. 2001.

MORÁN, Emílio F. A ecologia humana das populações da Amazônia. Petrópolis, RJ: Vozes, 1990.

MURRIETA, Rui Sérgio Sereni. Dialética do sabor: alimentação, ecologia e vida cotidiana em comunidades ribeirinhas da Ilha de Ituqui, Baixo Amazonas, Pará. Revista de Antropologia, São Paulo, v. 44, n. 2, 2001.

MURRIETA, Rui Sérgio Sereni et al. Estratégias de subsistência de uma população ribeirinha do rio Marajóaçu, Ilha de Marajó, Brasil. Boletim do Museu Paraense Emílio Goeldi: Série Antropológica, v. 5, n. 2, 1989.

NERI, Marcelo Côrtez; VAZ, Fábio Monteiro; SOUZA, Pedro Herculano Guimarães Ferreira de. Efeitos macroeconômicos do programa bolsa família: uma análise comparativa das transferências sociais. In: CAMPELLO, T.; NERI, M. C. (Org.). Programa Bolsa Família: uma década de inclusão e cidadania. Brasília: Ipea, 2013.

ORGANIZAÇÃO DAS NAÇÕES UNIDAS (ONU). Nações Unidas- Declaração do Milénio. Cimeira do Milénio. Nova lorque: ONU, set. 2000.

OSORIO, Rafael Guerreiro; SOUZA, Pedro H. G. Ferreira de. O Bolsa Família depois do Brasil Carinhoso: uma análise do potencial de redução da pobreza extrema. IPEA - Nota técnica n. 14. Brasília, dez. 2012.

PAES-SOUSA, Rômulo; SANTOS, Leonor Maria Pacheco; MIAZAKI, Édina Shisue. Effects of a conditional Cash Transfer Programme on child nutrition in Brazil. Bull World Health Organ, v. 89, 2011.

PHILIPPI, Sônia Tucunduva et al. Pirâmide alimentar adaptada: guia para escolha dos alimentos. Revista de Nutrição, Campinas, v. 12, n. 1, p. 65-80, jan./abr. 1999.

POULAIN, Jean-Pierre; PROENÇA, Rossana Pacheco da Costa. Reflexões metodológicas para o estudo das práticas alimentares. Revista de Nutrição, Campinas, v. 16, n. 4, out./dez. 2003.

SANTOS, Raphael Freitas. Vendas fiadas e outras práticas creditícias na economia colonial - Minas Gerais, século XVIII. Revista Angelus Novus, São Paulo, ano III, n. 4, p. 4-21, 2012.

SANTOS, Ronize da Silva; COELHO-FERREIRA, Maria. Estudo etnobotânico de Mauritia flexuosa L. f. (Arecaceae) em comunidades ribeirinhas do Município de Abaetetuba, Pará, Brasil. Acta Amazonica, Manaus, v. 42, n. 1, p. 1-10, mar. 2012.

SANTOS, Leonor Maria Pacheco; PASQUIM, Elaine Martins; SANTOS, Sandra Maria Chaves dos. Programas de transferência de renda no Brasil: um estudo multidimensional da implementação do Bolsa Escola, Bolsa Alimentação e Cartão Alimentação. Ciências e Saúde Coletiva, Brasília, v. 16, n. 3, p. 1821-1834, mar. 2011.

SAVE THE CHILDREN. Making cash count: lessons from cash transfer schemes in east and southern Africa for supporting the most vulnerable children and households. London: Save the Children UK / Help Age International / Institute of Development Studies, 2005. Disponível em: <https://www.ids.ac.uk/files/ MakingCashCountfinal.pdf>. Acesso em: 20 out. 2015.

SETTON, Maria da Graça Jacintho. A teoria do habitus em Pierre Bourdieu: uma leitura contemporânea. Revista Brasileira de Educação, Rio de Janeiro, n. 20, maio/ago. 2002.

SILVA, Maria da Conceição Monteiro da et al. Programa Bolsa Família e segurança alimentar das famílias beneficiárias: resultados para o Brasil e regiões. In: BRASIL. Ministério do Desenvolvimento Social e Combate à Fome. Avaliação de políticas e programas do MDS - resultados: Bolsa Família e Assistência Social. Brasília, DF: MDS; SAGI, 2007. p. 69-96. v. 2. 


\section{Sobre os autores:}

Elcio Costa Nascimento: Mestre em Agricultura Familiar e Desenvolvimento Sustentável pela Universidade Federal do Pará (UFPA) e graduado em Zootecnia pela Universidade Federal Rural da Amazônia (UFRA). Atua na área da produção animal nos seguintes temas: apicultura, meliponicultura, suinocultura e animais silvestres. Desenvolve discussões sobre a temática da Segurança Alimentar e Nutricional em comunidades tradicionais, quilombolas e indígenas. E-mail: elcioncosta@gmail.com

João Paulo Leão de Carvalho: Mestre em Agricultura Familiar e Desenvolvimento Sustentável (UFPA). Assessor Territorial de Inclusão Produtiva (NEDET/UFPA). E-mail: jpmarajo@gmail.com

Benedito Ely Valente da Cruz: Doutorando na Unesp (2013). Professor assistente nos cursos de Pedagogia e Geografia da Universidade Estadual do Pará (UEPA).E-mail: bvalente7@yahoo.com.br

Miqueias Freitas Calvi: Doutorando em Ambiente e Sociedade (NEPAM/UNICAMP). Professor da Faculdade de Engenharia Florestal, Campus Altamira (UFPA).E-mail: mcalvi@ufpa.br 